

\title{
Isolation of a 2-picolinic acid-assimilating bacterium and its proposed degradation pathway
}

\author{
Chunli Zheng ${ }^{\mathrm{a}}$, Qiaorui Wang ${ }^{\mathrm{a}}$, Yanli Ning ${ }^{\mathrm{b}}$, Yurui Fan ${ }^{\mathrm{a}}$, Shanshan Feng ${ }^{\mathrm{a}}$, Chi He ${ }^{\mathrm{a}, \mathrm{c},}$, Tian \\ C. Zhang ${ }^{\mathrm{d}}$, Zhenxing Shen ${ }^{\mathrm{a}}$
}

a Department of Environmental Science and Engineering, State Key Laboratory of Multiphase Flow in Power Engineering, School of Energy and Power Engineering, Xi'an Jiaotong University, Xi'an 710049, Shaanxi, PR China

b Xi'an Modern Chemistry Research Institute, Xi'an 710065, PR China

c School of Chemistry, Cardiff University, Main Building, Park Place, Cardiff CF10 3AT, UK

d 205D, PKI, Civil Engineering Department, University of Nebraska-Lincoln at Omaha campus, Omaha, NE 68182-0178, USA

\section{G R A P H I C A L A B S T R A C T}

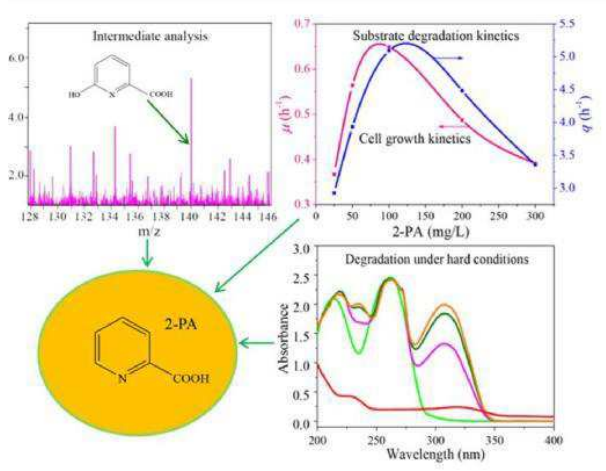

\section{A R T I C L E I N F O}

\section{Keywords:}

2-Picolinic acid

Burkholderia sp.

FT-ICR-MS

ATR-FTIR

Biodegradation pathway

\begin{abstract}
A B S T R A C T
Burkholderia sp. ZD1, aerobically utilizes 2-picolinic acid as a source of carbon, nitrogen and energy, was iso-lated. ZD1 completely degraded 2-picolinic acid when the initial concentrations ranged from 25 to $300 \mathrm{mg} / \mathrm{L}$. Specific growth rate $(\mu)$ and specific consumption rate $(q)$ increased continually in the concentration range of $25-100 \mathrm{mg} / \mathrm{L}$, and then declined. Based on the Haldane model and Andrew's model, $\mu_{\max }$ and $\mathrm{q}_{\max }$ were cal-culated as 3.9 and $16.5 \mathrm{~h}^{-1}$, respectively. Fourier transform ion cyclotron resonance mass spectrometry (FT-ICR-MS) was used to determine the main intermediates in the degradation pathway. Moreover, attenuated total reflectance Fourier transform infrared spectroscopy (ATR-FTIR) was innovatively used to deduce the ring cleavage mechanism of $\mathrm{N}$-heterocycle of 2-picolinic acid. To our knowledge, this is the first report on not only the utilization of 2-picolinic acid by a Burkholderia sp., but also applying FT-ICR-MS and ATR-FTIR for exploring the biodegradation pathway of organic compounds.
\end{abstract}

Corresponding author at: Department of Environmental Science and Engineering, State Key Laboratory of Multiphase Flow in Power Engineering, School of Energy and Power Engineering, Xi'an Jiaotong University, Xi'an 710049, Shaanxi, PR China.

E-mail address: chi_he@xjtu.edu.cn (C.He). 


\section{Introduction}

Pyridine and its derivatives are important representatives of $\mathrm{N}$ heterocyclic aromatic compounds (Kaiser et al., 1996). Wastes con-taining large amounts of the pyridine ring are generated from mining industry, coal and shale oil processing, wood-preserving facilities, pharmaceutical, food, dye, and agriculture (Kaiser et al., 1996; Yao et al., 2013). It was reported that the concentration of pyridines in the wastewaters ranged from 20 to 300 $\mathrm{mg} / \mathrm{L}$, and pyridines were mainly from production of agricultural chemicals, drugs, dyestuffs and textile (Huang et al., 2017). Because of the heterocyclic structure, pyridine and its derivatives are more soluble in water than their homocyclic analogs, and thus, they can be transported more easily to the aquatic environ-ment and soil (Kaiser et al., 1996). Pyridine and its derivatives are classified as priority pollutants by the United States Environmental Protection Agency due to their carcinogenicity and toxicity (Yao et al., 2013). When men were treated orally with $1.8-2.5 \mathrm{~mL}$ of pyridine daily for up to two months, they experienced anorexia, nausea, vomiting, gastric, distress, headache, fatigue, faintness and depression (Buhler and Reed, 1990). Especially, two cases of liver and kidney damage and one death occurred. The probable oral lethal dose of pyridine was $0.5-5.0 \mathrm{~g} / \mathrm{kg}$ and Lethal Dose Low $\left(\mathrm{LDL}_{\mathrm{o}}\right.$ ) for man was $500 \mathrm{mg} / \mathrm{kg}$ p.o. (Buhler and Reed, 1990). For estuarine sediment microorganisms, median eff ect concentrations (EC50) of pyridine and pyridine deriva-tives were in the range of 0.027-49.1 mmol/L (Liu et al., 1998).

2-Picolinic acid (2-PA) is an important pyridine derivative, which is widely used in the production of medicine, pesticide, daily chemicals, and feed additives in livestock and poultry industry ( $\mathrm{Li}$ et al., 2005). Its hydrophilic nature (water solubility of $887 \mathrm{~g} / \mathrm{L}$ at $20^{\circ} \mathrm{C}$ ) can do great damage to the environment (Tian and $\mathrm{Li}, 2005$ ). Till now several stu-dies have shown that aerobic biodegradation is an eff ective method to remove 2-picolinic acid from water (Kaiser et al., 1996; Yao et al., 2013; Zheng et al., 2009a), in which the microorganisms mainly belong to the genera of Arthrobacter (Khasaeva et al., 2011; Siegmund et al., 1990) and Streptomyces (Zheng et al., 2009a). Currently, the knowledge gap exists on biodegradation of 2picolinic acid with new strains. Particu-larly, information is not available on the kinetics of microbial growth and substrate utilization as well as metabolic pathway with the new strains under different conditions. Obtaining a strain belonging to a different genus and comparing it with previously reported strains (Khasaeva et al., 2011; Siegmund et al., 1990; Zheng et al., 2009a) are of scientific significance since it will be helpful for researchers to es-tablish a databank on how many kinds of microbes can utilize 2-pico-linic acid in nature.

To fill the knowledge gap, a new 2-picolinic acid-assimilating strain was isolated, and cell morphology and strain identification were carried out. The kinetics of cell growth and substrate consumption was studied systematically. The main intermediates in the degradation pathway were determined and the ring cleavage mechanism of $\mathrm{N}$-heterocycle of 2-picolinic acid was deduced. The objectives of this paper were to quantitatively describe the capacity of the as-isolated strain on removal of 2-picolinic acid from water, explore how the as-isolated strain transfers 2-picolinic acid into carbon dioxide and water, and finally evaluate the implications of applying this as-isolated strain for 2-picolinic acid-loaded wastewater treatment and site remediation.

\section{Materials and methods}

\subsection{Chemicals}

2-Picolinic acid (purity 99\%), 6-hydroxypicolinic acid (purity 99\%), 2,5-dihydroxypyridine and a-oxoglutaric acid (purity 99\%) were ob-tained from J \& K Scientific Ltd. (Beijing, China). All these substrates were chromatographic grade. Other chemicals with analytical grade were purchased from Tianjin Kermel Chemical Reagent Co., Ltd., China. Ultrapure water was produced from a UPT-II system (Ulupure Science and Technology Co., Ltd., China).

\subsection{Enrichment, isolation and identification of strain ZD1}

The activated sludge used in this work was collected from a was-tewater treatment plant (located in Xi'an, China) that treated waste-water contaminated with 2-picolinic acid. A certain volume $(10 \mathrm{~mL})$ of the activated sludge were aseptically added to $90 \mathrm{~mL}$ of the sterilized MS medium (Zheng et al., 2007) in a $250-\mathrm{mL}$ flask. The MS medium contained (per liter): $\mathrm{Na}_{2} \mathrm{HPO}_{4} \cdot 12 \mathrm{H}_{2} \mathrm{O}, 7 \mathrm{~g} ; \mathrm{KH}_{2} \mathrm{PO}_{4}, 1 \mathrm{~g} ; \mathrm{CaCl}_{2} \cdot 2 \mathrm{H}_{2} \mathrm{O}, 10 \mathrm{mg} ; \mathrm{FeCl}_{3}, 2 \mathrm{mg}$; and $\mathrm{MgSO}_{4} \cdot 7 \mathrm{H}_{2} \mathrm{O}, 20 \mathrm{mg}$. The $\mathrm{pH}$ of the MS medium was adjusted to 7.0. The 250-mL flask was supplemented with 2-picolinic acid to a final concentration of $100 \mathrm{mg} / \mathrm{L}$ and incubated under the aerobic condition in a rotary shaker (ZHWY-2102C, Zhicheng Analytical Instrument Manufacturing Co., Ltd., Shanghai, China) at $180 \mathrm{rpm}$ and $30^{\circ} \mathrm{C}$. When the culture became obviously turbid, $10 \mathrm{~mL}$ of the culture was transferred to $90 \mathrm{~mL}$ fresh MS medium in a new 250-mL flask with $100 \mathrm{mg} / \mathrm{L} 2$-picolinic acid. This operation was repeated until the degradation of 2-picolinic acid came to a stable level, and then the culture was diluted with sterilized $\mathrm{NaH}_{2} \mathrm{PO}_{4}-\mathrm{K}_{2} \mathrm{HPO}_{4}$ buffer $(\mathrm{pH}=$ 7.0) and spread onto agar (1.5\%) plates with MS medium and $100 \mathrm{mg} / \mathrm{L} \mathrm{2-}$ picolinic acid. The agar plates were incubated at $30{ }^{\circ} \mathrm{C}$ for $2-3 \mathrm{~d}$. There were three colonies appearing on the agar plates and stain ZD1 was selected for the further study. The $16 \mathrm{~S}$ rDNA sequence of strain ZD1 was amplified by PCR with primers 27F (5'-AGTTTGATCMTGGC-TCAG-3') and 1492R (5'GGTTACCTTGTTA CGACTT-3').

\subsection{Growth kinetics and 2-picolinic acid degradation kinetics}

One loop of strain ZD1 on the agar plates was transferred aseptically to $100 \mathrm{~mL}$ sterilized MS medium in a 250-mL flask with $100 \mathrm{mg} / \mathrm{L}$ 2-picolinic acid. After $12 \mathrm{~h}$ of cultivation, $10 \mathrm{~mL}$ of the culture was aseptically inoculated into $90 \mathrm{~mL}$ sterilized MS medium in a $250-\mathrm{mL}$ flask. The flask was supplemented with 2-picolinic acid at different initial concentrations ranged from 25 to $300 \mathrm{mg} / \mathrm{L}$. These cultures were incubated on a rotary shaker $(30$ $\left.{ }^{\circ} \mathrm{C}, 180 \mathrm{rpm}\right)$. All cultivations were repeated three times. Data were analyzed statistically by Origin 7.0 (Origin lab, USA) and the error bars depicted the 95\% confidence in-tervals. A flask with the same amount of the autoclaved cells $\left(20 \mathrm{~min}, 120{ }^{\circ} \mathrm{C}\right)$ was used as abiotic degradation. Samples were withdrawn periodically for the analysis of 2-picolinic acid concentration, total or-ganic carbon (TOC), growth of strain ZD1, and dehydrogenase activity (DHA). Prior to the analysis of 2-picolinic acid concentration, TOC and DHA, samples were centrifuged under $15^{\circ} \mathrm{C}$ at $12,000 \mathrm{rpm}$ for $20 \mathrm{~min}$ to collect the supernatant, which then was filtered through a $0.22 \mu \mathrm{m}$-pore-size membrane (G-Biosciences Geno Technology Inc., USA) to re-move the biomass. Degradation of 2-picolinic acid under diff erent $\mathrm{pH}$, temperatures and salinities were also investigated.

\subsection{Preparation of the resting cells}

One loop of Strain ZD1 stock culture on the agar plate was trans-ferred aseptically to $100 \mathrm{~mL}$ sterilized MS medium in a 250 -mL flask with $200 \mathrm{mg} / \mathrm{L}$ 2-picolinic acid served as a sole source of carbon, ni-trogen and energy. The culture was incubated on a rotary shaker at $30^{\circ} \mathrm{C}$ and $180 \mathrm{rpm}$. The culture in the late exponential phase was aseptically centrifuged at $12,000 \mathrm{rpm}$ for 20 min and under $4{ }^{\circ} \mathrm{C}$ to collect cells. The cells were washed twice with sterilized ultrapure water $(\mathrm{pH}=7.0$ and electrical resistivity of $18 \mathrm{~m} \Omega \mathrm{cm}$ ). The resting cells $(100 \mathrm{mg}$, wet cell weight) were suspended in $10 \mathrm{~mL}$ of sterilized phosphate buffer $\left(\mathrm{Na}_{2} \mathrm{HPO}_{4}-\mathrm{KH}_{2} \mathrm{PO}_{4}, \mathrm{pH}=7.0\right)$ and then incubated with $50 \mathrm{mg} / \mathrm{L}$ of 2-picolinic acid at $30{ }^{\circ} \mathrm{C}$ and $180 \mathrm{rpm}$. Samples were taken regularly from the cultures and centrifuged at $12,000 \mathrm{rpm}$ for 20 min and under $4{ }^{\circ} \mathrm{C}$ to collect supernatant. The supernatant was filtered through a $0.22 \mu \mathrm{m}$-pore-size membrane. After removal of the biomass, some supernatant was directly used for the analysis of total 
organic carbon (TOC) and ammonia concentrations, whereas other supernatant was concentrated by freeze-drying (Boyikang Lab Instrument Co., Ltd., Beijing, China) at $-60{ }^{\circ} \mathrm{C}$, vacuum degree $12 \mathrm{~Pa}$ for $48 \mathrm{~h}$. The concentrated samples were analyzed by FT-ICR-MS and ATR-FTIR. The same setup was used for the experiments of 6-hydroxy picolinic acid, 2,5dihydroxypyridine, and oxoglutaric acid degradation by the resting cells of ZD1.

\subsection{Analysis}

Residual 2-picolinic acid concentration was determined at $265 \mathrm{~nm}$ by HPLC (S500, Sykam, Germany) using a Pinnacle II C18 $(5 \mu \mathrm{m}, 250 \mathrm{~mm} \times$ $4.6 \mathrm{~mm}$ ) (Restek Corporation, Bellefonte, PA, USA). The mobile phase was a mixture of water: methanol (v/v, 90: 10) containing $0.2 \%$ of formic acid. The flow rate was $1 \mathrm{~mL} / \mathrm{min}$ and the column temperature was $30^{\circ} \mathrm{C}$. FT-ICR-MS analyses were performed using a $9.4 \mathrm{~T}$ Solari X FT-ICR mass spectrometer from Bruker Daltonics (USA). The FT-IR spectra were measured on a Bruker Tensor 27FT-IR spec-trophotometer (Germany) in Attenuated Total Reflection (ATR, MIRacle, PIKE Co., USA) mode. The resolution of the FTIR was $4.0 \mathrm{~cm}^{-1}$. The scans number accumulated was 20 . The TOC contents were determined using a multi N/C2100 analyzer (Analytik Jena AG, Germany) (Zheng et al., 2009b). Ammonia concentration was measured by a standard method (Zheng et al., 2009c). DHA was analyzed by TTC $(2,3,5-$ triphenyltetramlium chloride) (Tluczkiewicz et al., 2016).

\section{Results and discussion}

\subsection{Isolation and characterization}

A strain able to utilize 2-picolinic acid as a sole source of carbon, nitrogen and energy under aerobic condition was isolated. SEM pho-tography shows that the morphology of this strain was baculiform with a size of 1-2 $\mu \mathrm{m}$. After incubation on the agar culture medium for $3 \mathrm{~d}$ at $30^{\circ} \mathrm{C}$, the colony was milk white, rounded protuberance, translucent, and smooth with regular edge. A phylogenetic tree was constructed, and it was found that this strain was related to Burkholderia sp. The homology between this strain and Burkholderia sp. C10 (2010) reached 99\%. Thus it was identified as Burkholderia sp. and named as ZD1. The gene bank accession number for strain ZD1 is KP900019. Burkholderia sp. is widely found in soil (Compant et al., 2008), in activated sludge (Wang et al., 2010), and on human skin (Vandamme et al., 2007). Several studies have shown that Burkholderia sp. is capable of degrading various organic pollutants under aerobic conditions including phenol (Dobslaw and Engesser, 2015), phenanthrene (Jia et al., 2009), qui-nolone (Quan et al., 2000). However, reports on the utilization 2pi-colinic acid by Burkholderia sp. are still very few.

\subsection{Degradation and growth kinetics}

The cell growth of ZD1, the consumption of 2-picolinic acid and TOC removal results were shown in Fig. 1. After 12 h, 2-picolinic acid was degraded completely. However, the TOC removal rate was only $15 \%$, which indicated that 2-picolinic acid was transformed into other substances. After 24 $\mathrm{h}$, the TOC removal rate reached $99 \%$, suggesting that these substances were finally mineralized into carbon dioxide and water. DHA reached a maximum at $24 \mathrm{~h}$.

Fig. 2a-e shows the cell growth of strain ZD1 and 2-picolinic acid degradation when the initial concentration of 2-picolinic acid in MS medium ranged from 25 to $300 \mathrm{mg} / \mathrm{L}$. The degradation rate corre-sponding to initial concentrations of $25,50,100,200$ and $300 \mathrm{mg} / \mathrm{L}$ was $97.9 \%, 99.0 \%, 98.0 \%$, $99.0 \%$, and $95.6 \%$, respectively. It is noted here that no abiotic degradation happened. Estimated values of the specific growth rate $(\mu)$ based on linear and logistic models (Ghosh et al., 2014) were listed in Table 1. Here, $\mu$ was determined through linear regression. Fig. $2 \mathrm{f}$ demonstrates that the logistic model pr

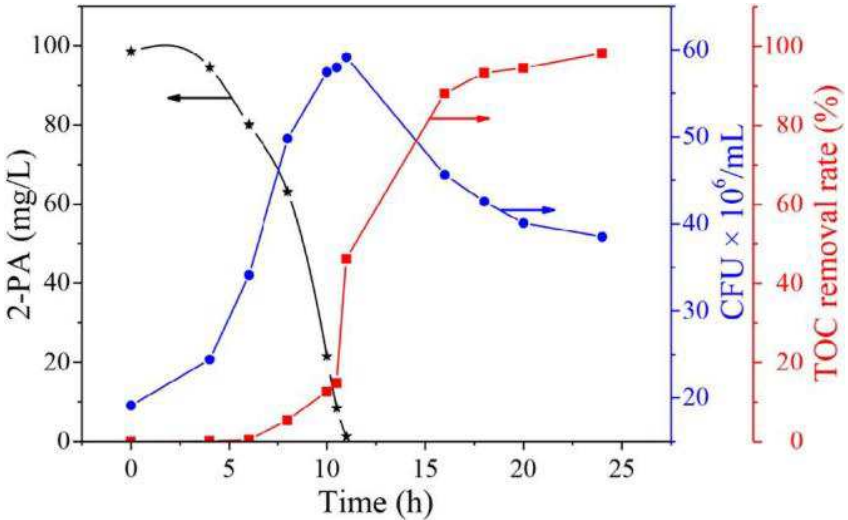

Fig. 1. Curves described the cell growth of Burkholderia sp. ZD1, degradation of 2-pico-linic acid (2-PA) and TOC removal rate (initial concentration of 2-picolinic acid in MS medium was $100 \mathrm{mg} / \mathrm{L}$, temperature of $30{ }^{\circ} \mathrm{C}, \mathrm{pH}$ of $7.0,0 \%$ salinity $(\mathrm{w} / \mathrm{v}, \mathrm{NaCl})$ ). Data were analyzed statistically and the error bars depicted the $95 \%$ confidence interval. Each data was repeated three times.

a good fit for the entire growth profile (including the lag and log phase growth data) up to $\mathrm{N}_{\text {max. }}$. The linear model could only fit the log phase data. Table 1 shows that the values of $\mu$ based on logistic model were higher than those calculated from the linear model at any 2-picolinic acid concentrations. In order to obtain the maximum specific growth rate $\left(\mu_{\max }\right)$, the Haldane model was used (Fig. 3). The value of $\mathrm{R}^{2}$ was 0.987 , which demonstrated that the experimental data were well cor-related by the Haldane model. By using a non-linear regression analysis, the kinetic parameters were as followed: $\mu_{\max }$ $=3.9 \mathrm{~h}^{-1}, \mathrm{KS}_{\mathrm{S}}=221.6 \mathrm{mg} / \mathrm{L}$, and $\mathrm{K}_{\mathrm{i}}=35.5 \mathrm{mg} / \mathrm{L}$.

Based on the degradation data shown in Fig. 2a-e, the specific substrate consumption rate (q) was calculated. Fig. 3 shows the re-lationship between $\mathrm{q}$ and the initial concentrations of 2-picolinic acid. It was observed that the values of q increased continually at the initial substrate concentration of 25$100 \mathrm{mg} / \mathrm{L}$, and then declined at $100-300 \mathrm{mg} / \mathrm{L}$. As seen in Table 1 , the values of logistic model based $\mu$ also reached the peak at $100 \mathrm{mg} / \mathrm{L}$ and then decreased. Therefore, it can be concluded when the initial concentration of 2picolinic acid in MS medium was higher than $100 \mathrm{mg} / \mathrm{L}$, the inhibitory eff ect occurred. Based on Fig. 3, the maximum specific consumption rate $\left(\mathrm{q}_{\max }\right)$ was calculated to be $16.5 \mathrm{~h}^{-1}$ with $\mathrm{R}^{2}$ of 0.900 , suggesting a good fit. So far there are only a few reports on the aerobic degradation of 2-picolinic acid by microbes (Kaiser et al., 1996; Yao et al., 2013; Zheng et al., 2009a). In these limited reports, the values of $\mu_{\max }$ and $\mathrm{q}_{\max }$ were not given. Therefore, it is hard to compare the growth kinetics of strain ZD1 and its degradation capacity with other 2-picolinic acid assimilating strains. We have reported a nitrobenzene-assimilating strain which was identified as R. Mucilaginosa (Zheng et al., 2008). R. mucilaginosa uti-lized nitrobenzene as a sole source of carbon, nitrogen and energy under aerobic conditions. The value of $\mathrm{q}_{\max }$ was calculated to be $1.5 \mathrm{~h}^{-1}$ based on the Andrew's model. After immobilized R. mucilagi-nosa on a kind of polyurethane foam, its degrading capacity was en-hanced largely in which the value of qmax equaled to $6.0 \mathrm{~h}^{-1}$ (Zheng et al., $2009 \mathrm{~b}$ ). As mentioned above, it is hardly to compare the growth activity of strain ZD1 and its degradation ability with other 2-picolinic acid assimilating strains since for other 2-picolinic acid assimilating strains the data of $\mu, \mu_{\max }$, $\mathrm{q}$ and $\mathrm{q}_{\max }$ are still absent. However, based on the values of $\mu$, $\mathrm{q}$ and $\mathrm{qmax}$ released by our previous study (Zheng et al., 2009b, 2008), it might be concluded that the growth activity of strain $\mathrm{ZD} 1$ and its degrading capacity is really high and within the expecta-tion.

\subsection{Degradation of 2-picolinic acid under diff erent conditions}

The degradation of 2-picolinic acid by strain ZD1 under diff erent 

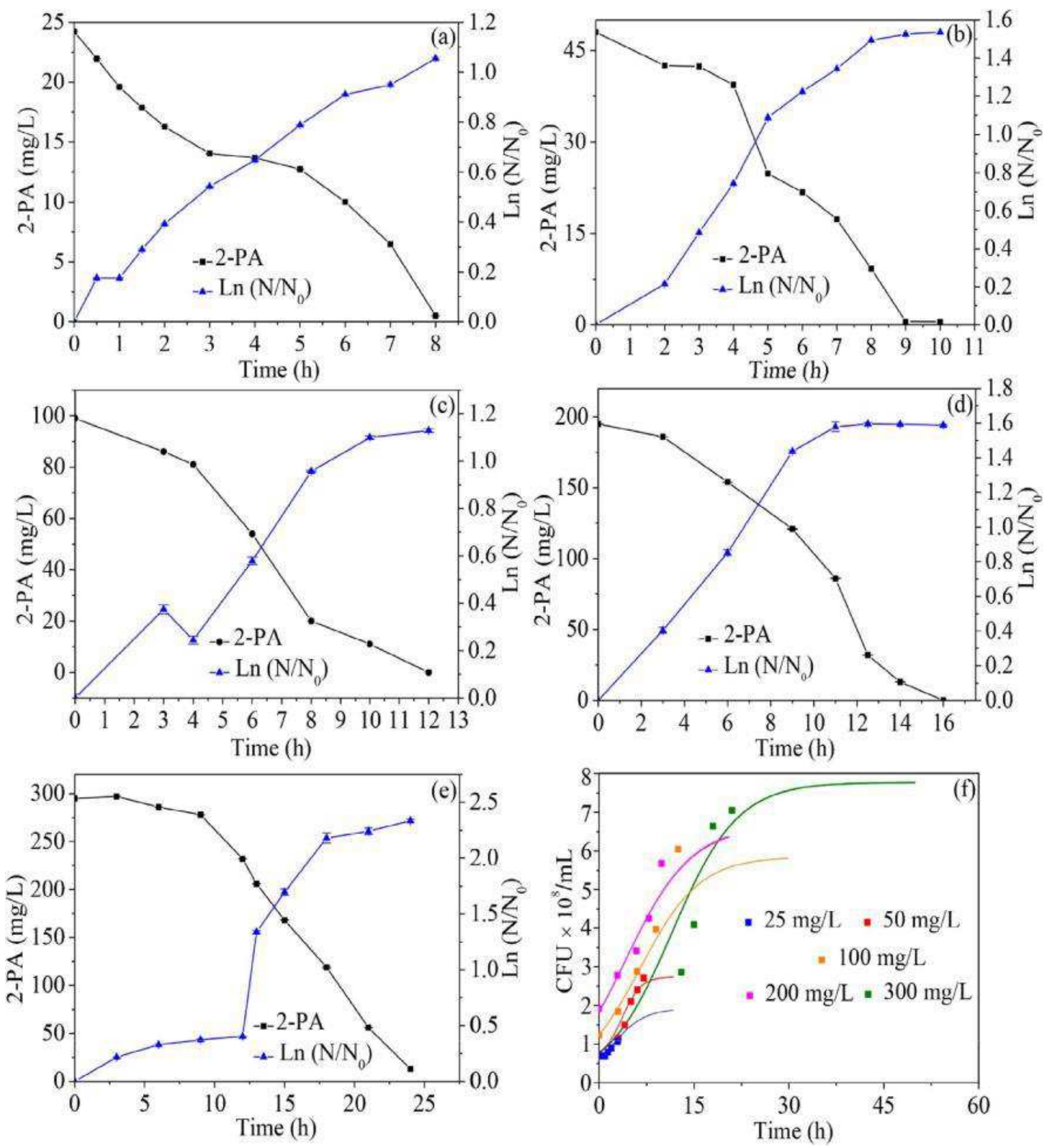

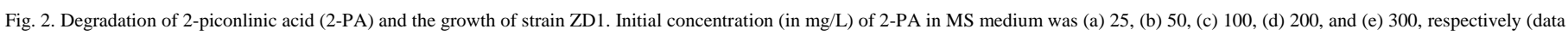

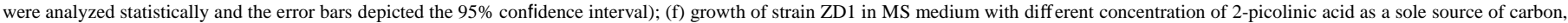
nitrogen and energy. Each data was the mean value of triplicates $(n=3)$.

$\mathrm{pH}$, temperatures and salinities was investigated in order to evaluate the bioactivity of strain ZD1 under hard conditions, as shown in Fig. 4. Strain ZD1 exhibited a good activity at a relatively wide $\mathrm{pH}$ and tem-perature range. However, the tolerance of strain ZD1 towards salinity was relatively low, and strain ZD1 can survive at salinity less than $1 \%(\mathrm{w} / \mathrm{v}, \mathrm{NaCl})$. Interestingly, even under low temperature $\left(4^{\circ} \mathrm{C}\right)$ and strong acidic conditions $(\mathrm{pH}=3.0)$, strain ZD1 also kept active. Ul-traviolet spectra show that after $4 \mathrm{~d}, 2$ picolinic acid (A265) degraded slightly and simultaneously a new compound (A310) emerged. When the reaction time was prolonged to $8 \mathrm{~d}$, the peak intensity of 2-picolinic acid almost kept unchanged compared to it shown in 4 $\mathrm{d}$, however, the peak intensity at $\mathrm{A}_{310}$ was a little bit higher than it shown in $4 \mathrm{~d}$. With the increase in reaction time, the peak intensity at $\mathrm{A}_{310}$ began to ob-viously decline after $12 \mathrm{~d}$. After $15 \mathrm{~d}$ all the peaks disappeared and the TOC removal was more than $98 \%$ (not shown). These results demon-strated that 2-picolinic acid was finally mineralized and the new com-pound $\left(\mathrm{A}_{310}\right)$ was an intermediate in the degradation pathway. Based on the values of $\mu_{\max }$ and $\mathrm{q}_{\max }$ as well as the degradation capacity under severe conditions, it can be concluded that strain ZD1 has a significant potential to biologically treat 2picolinic acid-loaded wastewater and may be used in remediation 2-picolinic acid contaminated sites. It is noted here that the substance ( $\left.\mathrm{A}_{310}\right)$ was identified as 6-hydroxy 
Table 1

Kinetic parameters for 2-picolinic acid degradation by strain ZD1.

\begin{tabular}{|c|c|c|c|c|c|c|c|}
\hline \multirow{2}{*}{$\begin{array}{l}\mathrm{Ce}_{\mathrm{e}} \\
(\mathrm{mg} / \mathrm{L})\end{array}$} & \multirow{2}{*}{$\begin{array}{l}\text { Initial No } \\
(\mathrm{CFU} / \mathrm{mL})\end{array}$} & \multirow{2}{*}{$\begin{array}{l}\mathrm{N}_{\text {max }} \\
(\mathrm{CFU} / \\
\mathrm{mL})\end{array}$} & \multicolumn{2}{|c|}{ Logistic model } & \multicolumn{2}{|c|}{ Linear model } & \multirow{2}{*}{$\begin{array}{l}\text { Yield } \\
\text { (CFU/ } \\
\mathrm{mg})^{*}\end{array}$} \\
\hline & & & $\mu\left(\mathrm{h}^{-1}\right)$ & $\mathrm{R}^{2}$ & $\mu\left(h^{-1}\right)$ & $\mathrm{R}^{2}$ & \\
\hline 25 & $7.05 \mathrm{E}+07$ & $\begin{array}{l}1.95 \mathrm{E} \\
+08\end{array}$ & 0.367 & 0.993 & 0.147 & 0.985 & $\begin{array}{l}1.38 \mathrm{E} \\
+10\end{array}$ \\
\hline 50 & $7.05 \mathrm{E}+07$ & $\begin{array}{l}3.28 \mathrm{E} \\
+08\end{array}$ & 0.564 & 0.986 & 0.193 & 0.928 & $\begin{array}{l}1.29 \mathrm{E} \\
+10\end{array}$ \\
\hline 100 & $1.91 \mathrm{E}+08$ & $\begin{array}{l}5.61 \mathrm{E} \\
+08\end{array}$ & 0.649 & 0.959 & 0.147 & 0.970 & $\begin{array}{l}1.23 \mathrm{E} \\
+10\end{array}$ \\
\hline 200 & $1.22 \mathrm{E}+08$ & $\begin{array}{l}6.24 \mathrm{E} \\
+08\end{array}$ & 0.487 & 0.955 & 0.153 & 0.983 & $\begin{array}{l}1.22 \mathrm{E} \\
+10\end{array}$ \\
\hline 300 & $7.50 \mathrm{E}+07$ & $\begin{array}{l}7.75 \mathrm{E} \\
+08\end{array}$ & 0.391 & 0.975 & 0.201 & 0.988 & $\begin{array}{l}1.19 \mathrm{E} \\
+10\end{array}$ \\
\hline
\end{tabular}

* Yield (CFU/mg) equals to CFU/mL divided by VSS (mg/mL).

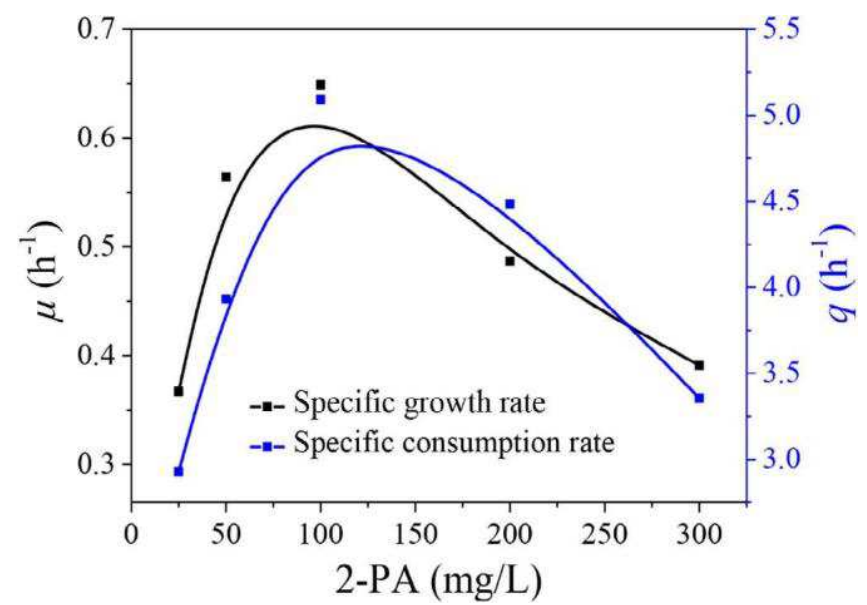

Fig. 3. Relationships between specific growth rate/specific consumption rate and initial 2 picolinic acid (2-PA) concentrations. Each data was the mean value of triplicates $(n=3)$.

picolinic acid by FT-ICR-MS. Many studies have shown that during the aerobic microbial breakdown of heterocyclic substrates, the most common mode of initial attach on the aromatic ring is hydroxylation of carbon adjacent to the heteroatom (Kaiser et al., 1996; Yao et al., 2013).

\subsection{Degradation pathway of 2-picolinic acid by strain ZD1}

Electrospray ionization coupled to Fourier transform ion cyclotron resonance mass spectrometry (ESI FT-ICR-MS) enables the identifica-tion of molecular formula with extremely high mass resolution powers $(>300,000)$ and mass accuracy $(<1 \mathrm{mg} / \mathrm{L}$ ) (Han et al., 2016; Herzsprung et al., 2016; Le Vot et al., 2016; Wozniak et al., 2008). Since each detected mass peak can be analyzed for possible elemental com-position based on predefined chemical constraints, ESI FT-ICR-MS is regarded as a viable method to directly ascertain molecular composi-tion of each constituent in a complicated matrix without any prior ex-traction or separation steps (Han et al., 2016; Herzsprung et al., 2016). Till now, ESI FT-ICR-MS has been successfully applied to various fields, including 1) environmental science, e.g., characterization of organic matter at the detailed molecular level in natural waters (Altieri et al., 2009b; Herzsprung et al., 2016; Lv et al., 2016; Wozniak et al., 2008) and refinery wastewater (Fang et al., 2017), atmospheric dissolved organic nitrogen in precipitation (Altieri et al., 2009a), and organo-sulfates in atmospheric samples) (Schmitt-Kopplin et al., 2010); 2) medicine industry (e.g., investigation of the characteristic fragment ions of phillyrin) (Lin et al., 2016); 3) biology (e.g., identification of peptide de novo amino acid sequencing for a seven-protein mixture)
(Guan et al., 2017), and characterization of the covalent interactions between cisplatin and Cox17-a key copper chaperone protein (Li et al., 2016); and 4) energy industry (e.g., analysis of oxygen compounds in the total organic acid content of crude oils) (Rojas-Ruiz and Orrego-Ruiz, 2016).

Fourier transform infrared spectroscopy (FTIR) has been used for decades to investigate the structure and bonding of chemicals. It has many desirable features such as simple sample preparation, few sam-ples requirement, delivering reliable and fast results and being non-destructive (Banas et al., 2017; Özgenc et al., 2017). Currently, with the development of IR reflectance technique such as attenuated total re-flectance (ATR), FTIR is capable of directly measuring substances in solid (Banas et al., 2017) or liquid state (Zhang et al., 2017). Therefore, the application of ATR-FTIR has been extended to many fields such as monitoring the solution concentration during a cooling crystallization process (Zhang et al., 2017), distinguishing 150 tablets with or without lactose (Banas et al., 2017), determining changes in the chemical structure of heat-treated woods (Özgenc et al., 2017), and exploring phosphate adsorption mechanisms at the ferrihydrite-water interface (Arai and Sparks, 2001).

Based on the characteristics of ESI FT-ICR-MS and ATR-FTIR, we hypothesized that these technologies can be applied to a new field, that is, deduction of microbial metabolism of aromatic ring compounds under aerobic conditions. The justifications are as follows: 1) ESI is regarded as a "soft" ionization technique as it produces minimal frag-mentation of the analytes, and thus, allows for the detection of intact molecules (Wozniak et al., 2008). Moreover, FT-ICR allows for direct injection; thus more concise and accurate raw data of intermediates in the biodegradation pathway can be obtained as compared to liquid or gas chromatographic mass spectrometry, in which sample pretreatment is needed (Han et al., 2016). 2) During the biodegradation process of aromatic ring compounds under aerobic conditions, the polar groups such as hydroxyl and carboxyl are added to the aromatic ring under the catalysis of dioxygenases or monooxygenases, suggesting that the po-larity of intermediates is enhanced compared to parent compounds. Since FTIR is sensitive to polar groups, it may provide useful and sup-plementary information on the identification of intermediates once ESI FT-ICR-MS cannot capture any signals. It is noted here that the biode-gradation of aromatic ring compounds occurs in aqueous solution; thus, it is suitable to use infrared technique in ATR mode instead of tradi-tional transmission mode. To test our hypothesis, we combined ESI FT-ICR-MS and ATR-FTIR to determine the main intermediates in the de-gradation pathway and to deduce the ring cleavage mechanism of $\mathrm{N}$-heterocycle of 2-picolinic acid.

3.4.1. Hydroxylation of 2-picolinic acid to form 6-hydroxy picolinic acid The mass spectra of 2-picolinic acid, in which the greatest peak

magnitude located at $\mathrm{m} / \mathrm{z} 146.02130$ corresponded to $[\mathrm{M}+\mathrm{Na}]^{+}$, and the peak magnitude centered at $\mathrm{m} / \mathrm{z} 124.03934$ was related to [M

$+\mathrm{H}]^{+}$. 2-Picolinic acid underwent hydroxylation, and then 6-hydroxy picolinic acid was produced $(\mathrm{m} / \mathrm{z}$ at 162.01616 represented $[\mathrm{M}$

$+\mathrm{Na}^{+}$). Many studies have shown that during the aerobic microbial breakdown of heterocyclic substrates, the most common mode of initial attach on the aromatic ring is hydroxylation of carbon adjacent to the heteroatom (Kaiser et al., 1996; Yao et al., 2013; Zheng et al., 2009a).

3.4.2. Transformation of 6-hydroxy picolinic acid to 2,5-dihydroxypyridine Since 6-hydroxy picolinic acid was ascertained to be one of the in-termediates in the biodegradation pathway, it was used as a substrate to identify the consequent degrading product. A strong peak at m/z of 162.01616 ([M +

$\mathrm{Na}^{+}$) referring to 6-hydroxy picolinic acid when the reaction time was $0 \mathrm{~h}$. The peak at 163.01952 was isotopic peak of 6-hydroxy picolinic acid. After 8 h, 2,5-dihydroxypyridine with $\mathrm{m} / \mathrm{z}$ at $134.02110\left([\mathrm{M}+\mathrm{Na}]^{+}\right)$was produced, and simultaneously the peak intensity of 6-hydroxy picolinic acid became weaker. It can be con-cluded that 6-hydroxy picolinic acid was transformed to 2,5- 

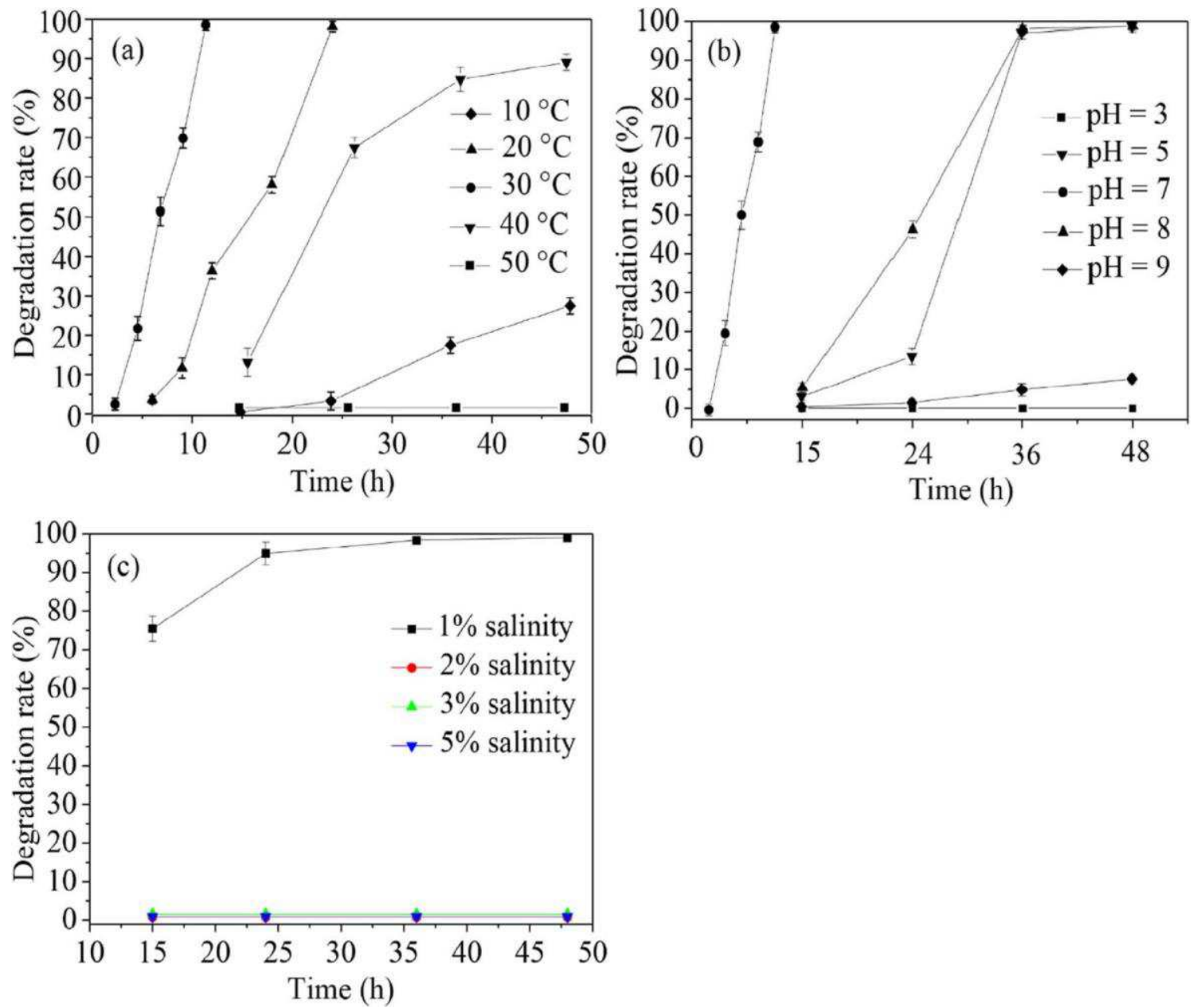

Fig. 4. Degradation of 2-picolinc acid by strain ZD1 under (a) diff erent temperatures, (b) different pH, and (c) diff erent salinities (w/v, NaCl). Data were analyzed statistically and the error bars depicted the $95 \%$ confidence interval. Each data was repeated three times.

dihydroxypyridine, which is consistent with the previous reports (Kaiser et al., 1996; Yao et al., 2013).

\subsubsection{Production of oxoglutaric acid from 2,5-dihydroxypyridine}

Since 2,5-dihydroxypyridine was ascertained to be one of the intermediates in the biodegradation pathway, it was used as a substrate to identify the consequent degrading product. 2,5-Dihydroxypyridine with two strong signals at $\mathrm{m} / \mathrm{z}$ of 223.07322 and 245.05553 respectively corresponding to the $[2 \mathrm{M}+\mathrm{H}]^{+}$and $[2 \mathrm{M}+\mathrm{Na}]^{+}$adducts were clearly detected when the reaction time was $0 \mathrm{~h}$. After $7 \mathrm{~h}$, the peaks of 2,5-dihydroxypyridine disappeared, but new peaks located at $\mathrm{m} / \mathrm{z}$ of 147.02875 and 169.01078 emerged. The two peaks respectively at-tributed to the $[\mathrm{M}+\mathrm{H}]^{+}$and $[\mathrm{M}+$ $\mathrm{Na}]^{+}$adducts of oxoglutaric acid. These results suggested that 2,5dihydroxypyridine was transformed into oxoglutaric acid, which accords with the previous reports (Kaiser et al., 1996; Yao et al., 2013).

The mass error of the intermediates analysis by FT-ICR-MS was found lower than $2 \mathrm{mg} / \mathrm{L}$ and allowed a credible conversion of ex-perimental mass peaks into compound formulas with high confidence. It is noted here that during the degradation process ammonia was de-tected (not shown), which means that 2,5-dihydroxypyridine under-went ring cleavage and $\mathrm{N}$ atom was released from the $\mathrm{N}$-heterocycle.

\subsubsection{Ring cleavage of 2,5-dihydroxypyridine}

Till now there are few reports on how the ring of 2,5-dihydrox-ypyridine was opened to form oxoglutaric acid (Kaiser et al., 1996; Yao et al., 2013). The possible reason is that it is hard for mass spectra to detect the ring cleavage product since sometimes it is difficult to find out the optimal ionization conditions. In order to explore the ring cleavage mechanism of 2,5-dihydroxypyridine, we adopted the method as follows: first, we proposed that there may exist four ways for the ring open of 2,5dihydroxypyridine based on Kaiser et al. (1996), who summarized the metabolic pathways of $\mathrm{N}$-heterocyclic compounds in-cluding pyridine, quinolone, acridine and their derivatives under aerobic conditions. The heterocycle was opened by dioxygenases at the position between two carbon atoms (one $\mathrm{C}$ atom is located at ortho position to $\mathrm{N}$ atom while the other at meta position) or between $\mathrm{N}$ atom and its adjacent $\mathrm{C}$ atom (Kaiser et al., 1996). As for pathways I and IV, the ring cleavage of 2,5-dihydroxypyridine was assumed to happen between $\mathrm{C}_{5}$ and $\mathrm{C}_{6}$ or between $\mathrm{C}_{2}$ and $\mathrm{C}_{3}$, respectively. After the release of formamide (eNH $2 \mathrm{CHO}$ ) (Kaiser et al., 1996) the products for the two pathways would contain four carbon atoms only, which is obviously contradictory to the results given by FT-ICR-MS since oxoglutaric acid contains five carbon atoms. As for pathways II and III, the ring cleavage of 2,5-dihydroxypyridine was assumed to happen between $\mathrm{N}$ atom and its adjacent $\mathrm{C}$ atom, that is, $\mathrm{C}_{6}$ for pathway II and $\mathrm{C}_{2}$ for pathway III, respectively. After the release of $\mathrm{eNH}_{2}$ and hydrogenation (Kaiser et al., 1996) the products for pathways II and III would be oxoglutaric acid, which is in agreement with the results provided by FT-ICR-MS.

Next, we used the technology of Attenuated Total Reflectance FTIR to determine whether pathway II or III is correct. The band that appears at 1623 and $1436 \mathrm{~cm}^{-1}$ was attributed to pyridine ring skeleton stretching vibration. $\mathrm{CeO}$ stretching vibration was recognized by two sorption bands at 1159 and $1049 \mathrm{~cm}^{-1}$ as well as the band at 
$2312 \mathrm{~cm}^{-1}$ was assigned to $\mathrm{CO}_{2}$. After $6 \mathrm{~h}$ of degradation, the peaks of 2,5dihydroxypyridine disappeared, and a new band at $1648 \mathrm{~cm}^{-1}$ appeared, which was attributed to amide stretching vibration. It was found that only the product of 2,5-dihydroxypyridine ring cleavage based on way II possesses amide group.

Since oxoglutaric acid was ascertained to be one of the inter-mediates in the biodegradation pathway, it was used as a substrate to identify the consequent degrading product. Unfortunately, FT-ICR-MS did not provide any information. However, TOC analysis showed that oxoglutaric acid was finally mineralized into $\mathrm{CO}_{2}$ and $\mathrm{H}_{2} \mathrm{O}$. Based on the results provided by FTICR-MS, ATR-FTIR and TOC, the proposed biodegradation pathway of 2picolinic acid by strain ZD1 was pre-sented. 2-Picolinic acid firstly underwent hydroxylation to form 6-hy-droxy picolinic acid. Then 6-hydroxy picolinic acid was transformed into 2,5-dihydroxypyridine. Under the catalysis of dioxygenase, the ring of 2,5-dihydroxypyridine was opened in which the cleavage happened between $\mathrm{N}$ atom and $\mathrm{C}_{6}$. After the release of $\mathrm{eNH}_{2}$ and hydrogenation, oxoglutaric acid was produced and finally mineralized into carbon di-oxide and water.

Herein, the main intermediates were qualitatively analyzed, and the biodegradation process of 2-picolinic acid was described at molecular level. Based on the qualitative information, quantitative analysis will be done later by monitoring the concentration of each intermediate. Pure enzyme responsible for each biotransformation reaction in the de-gradation pathway will be extracted. Kinetics of enzyme-catalyzed re-actions will be established and the rate-limiting step in the degradation pathway will be found out. These future works might contribute to the construction of genic engineering strain and the field of biocatalysis. Moreover, both $\mu_{\max }$ and $\mathrm{q}_{\max }$ were calculated, which will be helpful for ascertaining organic and hydraulic shock loadings and as well as design of the corresponding wastewater treatment processes in the future.

\section{Conclusions}

This paper reported the aerobic degradation of 2-picolinic acid by Burkholderia sp. ZD1. Growth and degradation kinetics were studied. ZD1 exhibited a good activity under relative wide $\mathrm{pH}$ and temperature ranges. FTICR-MS and ATR-FTIR were used to deduce the biode-gradation pathway. To our knowledge, this is the first time to use FT-ICR-MS and ATR-FTIR in such a field. This work not only clarified the metabolic mechanism of 2picolinic acid but also may provide a new method for exploring the biodegradation pathway of organic com-pounds.

\section{Acknowledgements}

This work was supported by the National Natural Science Foundation of China (grant numbers 21307097, 21677114, 21477095), National Key R \& D Program of China (grant number 2016YFC0204201), Fundamental Research Funds for the Central Universities (grant numbers xjj2016046, xjj2017170) and China Postdoctoral Science Foundation (grant number 2016M602830). We would also thank very much to the editor and anonymous reviewers for their valuable opinions.

\section{References}

Arai, Y., Sparks, D.L., 2001. ATR-FTIR spectroscopic investigation on phosphate ad-sorption mechanisms at the ferrihydrite-water interface. J. Colloid Interface Sci. 241, 317-326.

Altieri, K.E., Turpin, B.J., Seitzinger, S.P., 2009a. Composition of dissolved organic nitrogen in continental precipitation investigated by ultra-high resolution FT-ICR mass spectrometry. Environ. Sci. Technol. 43, 6950-6955.

Altieri, K.E., Turpin, B.J., Seitzinger, S.P., 2009b. Oligomers, organosulfates, and nitrooxy organosulfates in rainwater identified by ultra-high resolution electrospray ionization FTICR mass spectrometry. Atmos. Chem. Phys. 9, 2533-2542.

Banas, A., Banas, K., Kalaiselvi, S.M.P., Pawlicki, B., Kwiatek, W.M., Breese, M.B.H., 2017. Is it possible to find presence of lactose in pharmaceuticals? - preliminary studies by ATRFTIR spectroscopy and chemometrics. Spectrochim. Acta, Part A 171, 280-286.

Buhler, D.R., Reed, D.J., 1990. Nitrogen and phosphorus solvents. In: Synder, R. (Ed.), Ethel Browning's Toxicity and Metabolism of Industrial Solvents. Elsevier Science Publishers B.V, Amsterdam, pp. 262-264.

Compant, S., Nowak, J., Coenye, T., Clément, C., Barka, E.A., 2008. Diversity and oc-currence of Burkholderia spp. in the natural environment. FEMS Microbiol. Rev. 32, 607-626.

Dobslaw, D., Engesser, K.H., 2015. Degradation of toluene by ortho cleavage enzymes in Burkholderia fungorum FLU100. Microb. Biotechnol. 8, 143-154.

Fang, Z., He, C., Li, Y.Y., Chung, K.H., Xu, C.M., Shi, Q., 2017. Fractionation and characterization of dissolved organic matter (DOM) in refinery wastewater by revised phase retention and ion-exchange adsorption solid phase extraction followed by ESI FT-ICR MS. Talanta 162, 466-473.

Ghosh, I., Jasmine, J., Mukherji, S., 2014. Biodegradation of pyrene by a Pseudomonas aeruginosa strain RS1 isolated from refinery sludge. Bioresour. Technol. 166, 548-558.

Guan, X.Y., Brownstein, N.C., Young, N.L., Marshall, A.G., 2017. Ultrahigh-resolution Fourier transform ion cyclotron resonance mass spectrometry and tandem mass spectrometry for peptide de novo amino acid sequencing for a seven-protein mixture by paired singleresidue transposed Lys-N and Lys-C digestion. Rapid Commun. Mass Spectrom. 31, 207217.

Han, F., Li, Y.T., Zhang, X.S., Song, A.H., Zhang, J.D., Yin, R., 2016. Comparative study of direct injection analysis and liquid chromatography mass spectrometry for identifi-cation of chemical constituents in Kudiezi injection by FT-ICR MS. Int. J. Mass Spectrom. 405, 3238.

Herzsprung, P., Hertkorn, N., von Tümpling, W., Harir, M., Friese, K., Schmitt-Kopplin, P., 2016. Molecular formula assignment for dissolved organic matter (DOM) using high-field FT-ICR-MS: chemical perspective and validation of sulphur-rich organic com-ponents (CHOS) in pit lake samples. Anal. Bioanal. Chem. 408, 2461-2469.

Huang, D., Liu, W., Wu, Z.L., Liu, G.M., Yin, H., Chen, Y.R., Hu, N., Jia, L., 2017. Removal of pyridine from its wastewater by using a novel foam fractionation column. Chem. Eng. J. 321, 151-158.

Jia, Y.H., Qu, Y.Y., Zhou, J.T., Li, A., Ai, F.F., 2009. Characteristics and enzyme purification of Burkholderia sp. AFF for phenanthrene biodegradation. Environ. Sci. Technol. 32, 21-24 (in Chinese).

Kaiser, J.P., Feng, Y.C., Bollag, J.M., 1996. Microbial metabolism of pyridine, quinoline, acridine, and their derivatives under aerobic and anaerobic conditions. Microbiol. Rev. 60, 483-498.

Khasaeva, F., Vasilyuk, N., Terentyev, P., Troshina, M., Lebedev, A.T., 2011. A novel soil bacterial strain degrading pyridines. Environ. Chem. Lett. 9, 439-445.

Le Vot, C., Bouaziz, M., Heninger, M., Boissel, P., Mauclaire, G., Mestdagh, H., Da Costa, F., Lemaire, J., 2016. Development of a transportable FT-ICR MS associated with a glow discharge ionization source. Int. J. Mass Spectrom. 407, 106-112.

Liu, S.M., Wu, C.H., Huang, H.J., 1998. Toxicity and anaerobic biodegradability of pyr-idine and its derivatives under sulfidogenic conditions. Chemosphere 36, 2345-2357.

Li, K.C., Zhang, H.B., Liu, J., Cao, X.J., Zhang, Y.M., 2005. Simultaneous determination of pyridine, 2-aminopyridine, 2-methylpyridine and 2-pyridinecarboxylic acid by re-versed phase high performance liquid chromatography. Chin. J. Anal. Chem. 33, 1580-1582 (in Chinese).

Li, L.J., Guo, W., Wu, K., Zhao, Y., Luo, Q., Zhang, Q.W., Liu, J.A., Xiong, S.X., Wang, F.Y., 2016. Identification of binding sites of cisplatin to human copper chaperone protein Cox17 by high-resolution FT-ICR-MS. Rapid Commun. Mass Spectrom. 30, 168-172.

Lin, Z.G., Lin, Z.W., Mu, Y.D., Yan, D., 2016. Comparison of collision-induced dissociation and electron-induced dissociation of phillyrin using FT-ICR MS. Spectrochim. Acta, Part A $167,84-88$.

Lv, J.T., Zhang, S.Z., Luo, L., Cao, D., 2016. Solid-phase extraction-stepwise elution (SPE-SE) procedure for isolation of dissolved organic matter prior to ESI-FT-ICR-MS ana-lysis. Anal. Chim. Acta 948, 55-61.

Özgenc, Ö., Durmaz, S., Boyaci, I.H., Eksi-Kocak, H., 2017. Determination of chemical changes in heat-treated wood using ATR-FTIR and FT Raman spectrometry. Spectrochim. Acta, Part A 171, 395-400.

Quan, X.C., Han, L.P., Wang, J.L., Shi, H.C., Qian, Y., 2000. Biodegradation of quinoline by immobilized Burkholderia pickettii sp. Chin. J. Environ. Sci. 44, 1041-1046 (in Chinese).

Rojas-Ruiz, F.A., Orrego-Ruiz, J.A., 2016. Distribution of oxygen-containing compounds and its significance on total organic acid content in crude oils by ESI negative ion FT-ICR MS. Energy Fuels 30, 8185-8191.

Schmitt-Kopplin, P., Gelencser, A., Dabek-Zlotorzynska, E., Kiss, G., Hertkorn, N., Harir, M., Hong, Y., Gebefugi, I., 2010. Analysis of the unresolved organic fraction in at-mospheric aerosols with ultrahigh-resolution mass spectrometry and nuclear mag-netic resonance spectroscopy: organosulfates as photochemical smog constituents. Anal. Chem. 82, 80178026.

Siegmund, I., Koenig, K., Andreesen, J.R., 1990. Molybdenum involvement in aerobic degradation of picolinic-acid by Arthrobacter-picolinophilus. FEMS Microbiol. Lett. 67, 281-284.

Tian, Y.Q., Li, W.H., 2005. A new process of synthesis of chromium-2-picolinate by chromic anhydride oxidation. Chem. Eng. 19,53-54 (in Chinese). Tluczkiewicz, I., Kuhne, R., Ebert, R.U., Batke, M., Schuurmann, G., Mangelsdorf, I. Escher, S.E., 2016. Inhalation TTC values: a new integrative grouping approach 
considering structural, toxicological and mechanistic features. Regul. Toxicol. Pharmacol. 78, 8-23.

Vandamme, P., Govan, J., LiPuma, J., 2007. Diversity and role of Burkholderia spp. In: Coenye, T., Vandamme, P. (Eds.), Burkholderia Molecular Microbiology and Genomics. Horizon, Bioscience, Norfolk, pp. 1-28.

Wang, Y.L., Yin, B., Hong, Y.G., Gu, J.D., 2010. Biodegradation of dimethyl phthalate by Burkholderia sp. DA2 isolated from marine sediments in the South China Sea. J. Trop. Oceanogr. 29, 71-75 (in Chinese).

Wozniak, A.S., Bauer, J.E., Sleighter, R.L., Dickhut, R.M., Hatcher, P.G., 2008. Technical Note: Molecular characterization of aerosol-derived water soluble organic carbon using ultrahigh resolution electrospray ionization Fourier transform ion cyclotron resonance mass spectrometry. Atmos. Chem. Phys. 8, 5099-5111.

Yao, Y.X., Tang, H.Z., Ren, H.X., Yu, H., Wang, L.J., Zhang, W., Behrman, E.J., Xu, P., 2013 Iron (II)-dependent dioxygenase and $\mathrm{N}$-formylamide deformylase catalyze the reactions from 5-hydroxy-2-pyridone to maleamate. Sci. Rep. 3, 3235-3245.

Zhang, F.K., Liu, T., Wang, X.Z., Liu, J.X., Jiang, X.B., 2017. Comparative study on ATRFTIR calibration models for monitoring solution concentration in cooling crystallization. J. Cryst. Growth 459, 50-55.

Zheng, C.L., Zhou, J.T., Wang, J., Qu, B.C., 2008. Isolation and characterization of a nitrobenzene degrading yeast strain from activated sludge. J. Hazard. Mater. 160, 194199

Zheng, C.L., Zhou, J.T., Wang, J., Qu, B.C., Wang, J., Lu, H., Zhao, H.X., 2009a. Aerobic degradation of 2-picolinic acid by a nitrobenzene-assimilating strain: Streptomyces sp. Z2. Bioresour. Technol. 100, 2082-2084.

Zheng, C.L., Zhou, J.T., Wang, J., Qu, B.C., Wang, J., Lu, H., Zhao, H.X., 2009b. Aerobic degradation of nitrobenzene by immobilization of Rhodotorula mucilaginosa in polyurethane foam. J. Hazard. Mater. 168, 298-303.

Zheng, C.L., Qu, B.C., Wang, J., Zhou, J.T., Wang, J., Lu, H., 2009c. Isolation and characterization of a novel nitrobenzene degrading bacterium with high salinity toler-ance: Micrococcus luteus. J. Hazard. Mater. 165, 1152-1158.

Zheng, C.L., Zhou, J.T., Zhao, L.H., Lu, H., Qu, B.C., Wang, J., 2007. Isolation and characterization of a nitrobenzene degrading Streptomyces strain from activated sludge. Bull. Environ. Contam. Toxicol. 78, 163-167. 